\title{
Research on Ink and Wash Elements in Graphic Design
}

\author{
Huaying Zhang \\ Shandong Institute of Labor and Vocational technology, Jinan, Shandong, 250013
}

Keywords: Ink and Wash Elements, Graphic Design, Application

\begin{abstract}
In recent years, the use of ink in the form of the performance of the design works more and more, from the perspective of the development of ink art or from the local design point of view, ink and design combination is of great significance. However, whether it is overwhelming design or design works on the exhibition, the use of ink elements seem to only reach the number of breakthroughs, memorable works are rare. Ink and ink elements as a special element carrying the essence of Chinese culture, its use in the graphic design of the level of China's domestic design development and improvement. Through the analysis, the author found that the use of ink and ink elements for the discovery of ink elements is not enough, the use of ink elements only in the surface and ink elements of the form of modern aesthetic concepts and other issues. I believe that the understanding of the elements of ink should not be confined to the ink material material presented in the form of beauty, or "white when the black" "image modeling" "line shape" these surface forms, or just some traditional Ink and drawing symbols of the graft combination, more importantly, to convey the ink embodied in the philosophical connotation, spiritual connotation and its modern culture in the traditional spirit, and so deep things. Only these deep elements can support the establishment of local design. In this regard, Japan's graphic design can give us a good reference, Japan's graphic design in the world is unique, with a strong national characteristics, but also widely recognized by the world. However, Japanese designers are not keen on the traditional form of copying, and even in the works rarely see the traditional graphics or patterns appear, on the contrary many designers of the graphics are very modern, such as Fukuda, The
\end{abstract}

\section{Introduction}

In recent years, the word word word rate is getting higher and higher, many industries are looking for old elements and the reconstruction of new elements as an important way to develop innovation in the field of literature scholars have put forward the same style and characteristics of the text is the old A new combination of elements. In the design world, the globalization of economy and the globalization of culture make us increasingly feel the importance of "Chinese design" in the pattern of contemporary world economic development, and will provide an important solution to the excavation and innovation of traditional old elements. China's ink art because of its unique position in Chinese culture has always been the focus of cultural and art circles. However, Japanese designers are not keen on the traditional form of copying, and even in the works rarely see the traditional graphics or patterns appear, on the contrary many designers of the graphics are very modern, such as Fukuda, The Really through which the Japanese nation's cultural spirit and philosophical spirit of these deep elements. Therefore, I believe that the use of ink elements to follow the principle of modern visual communication, inheritance deep ink elements, innovative surface ink elements. The use of visual communication principle to meet the graphic design of their own laws in order to convey the information, play the purpose of communication Innovative surface ink elements in order to make the traditional form of ink in line with the aesthetic requirements of modern society for the public to accept the deep elements of ink to make works more Profound, more intriguing, in order to establish a real "Chinese design." 


\section{Analysis of Ink Elements}

The appearance of ink and ink elements in graphic design is mostly as a symbol and symbolic, ink and ink elements in the graphic design of the symbolic content includes the following aspects in foreigners seem to represent the East and the West relative concept, oriental culture, oriental philosophy in Modern people seem to represent the traditional, traditional spirit, traditional culture in the ordinary people seem to represent a culture, elegance, taste in the city people seem to return, pastoral, free. So in the graphic design, people understand the ink elements more based on a symbol of understanding, for its consumption is also a symbol of consumption. "When the broad masses of people along the social level of development, and finally rich or achieve a higher status, they will also put forward cultural needs, this demand is to use symbols to show off this position." Therefore, the graphic design of the use of ink elements Easy to flow in the superficial and empty, only the water and ink blend of the body. How to avoid it first need a more comprehensive and rational view of ink elements. The semiotics suggests that the sign is composed of signifier and signifier, and the symbol can be divided into the surface structure image and the deep structure image. In this paper, the author in this article will be divided into the surface elements of ink and ink elements and deep ink elements to understand the two parts.

Deep ink element refers to the ink and the art of specific spiritual and cultural connotation, the so-called spiritual and cultural connotation is the ink art embodies the inherent nature of the nation. Ink and ink art represents the philosophical and aesthetic ideals of China and the East. The art of ink and ink is closely linked with the traditional philosophy and aesthetic philosophy of Confucianism, Buddhism and Taoism in China, or the Chinese ink painting is the artistic carrier of Chinese traditional culture. The pursuit of harmony, control, simplicity and implication of ink and ink art is in line with the traditional Chinese painting, Embodies the unique connotation of the Chinese nation and cultural tastes.

Natural, simple, simple aesthetic Chinese ink painting emphasizes love-oriented, emphasizing the natural expression of emotion, Zhuangzi that heaven and earth naturally own beauty, law, reason, people just listen to their natural, you can achieve the goal, this is Zhuangzi's "natural "Said. Chuang-tzu's view of "nature" is "still true", and Confucius's theory of light and light together constitute the basis of Chinese art advocating nature. Therefore, in order to pursue nature, Confucius advocates "painting", at this point, Confucianism and Taoism are consistent, "mysterious" and "prime", "quality" and "Park" is the core of Chinese aesthetic psychology. But also the aesthetic of the East is different from the West's unique, ink art embodies the Confucius Chong Su Shang Ya's aesthetic view and I pursue simple, simple aesthetic ideal.

\section{Ink Elements in the Graphic Design of the Reasons}

Graphic design for the "that is." In China is nearly two or three years to appear the term, formerly known as "business, layout, create". With regard to the definition of the concept of "graphic design", Mr. Wang Shizhi has made a more comprehensive exposition of his "World Modern Graphic Design History". Graphic design is a very important component of the design category. All the two- Film and television design activities are basically the contents of graphic design. In addition to the meaning of the activities on the plane, but also with the printing is closely related to the meaning, especially the production of print production of print works, especially the design of books, packaging design, advertising design, logo design, corporate image series design, font Design, layout of various publications, etc., which are the central content of graphic design. Mr. Wang Zhenti also from the perspective of the symbol, graphic design is also a symbol of the transmission is the plane of a few basic elements, including graphics, fonts, text, illustrations, colors, signs, etc. in a symbolic way to communicate Up to make it a mass production of printed matter, so that it has the function of accurate visual communication, while the audience to design to achieve the visual psychological satisfaction. Design is a purpose of planning, graphic design is one of these forms will be taken in the graphic design needs to use visual elements to spread ideas and plans, 
with words and graphics to convey information to the audience, so that people through these visual elements to understand The designer's vision and plan, this is the definition of the design.

Today, graphic design is increasingly becoming an important means of international communication, because the demand for communication, resulting in the same requirements of visual communication. And when the world of graphic design is increasingly convergence, the designers began to focus on the design of individual design and design issues, the traditional art symbols in those auspicious good wishes, simple true feelings, symbolic metaphor and implied It is a kind of traditional culture and style, and it is widely used in contemporary graphic design. It is a kind of traditional culture and style. In addition, postmodernism encourages a return to the richness and diversity of vision, in which human, regional, and historical sources are better developed. Postmodern design rethinks the personal style, national style and traditional style but it also inherits the modernist design for functional, structural, and formal exploration of the results. "The future trend of China's art design, certainly with the development trend of the world's art and design trends are consistent, but also have their own unique place. This unique place is reflected in the pursuit of ${ }^{`}$ design culture of belonging and identity.

\section{The Application of Ink and Wash Elements in Graphic Design}

The use of ink and ink elements in graphic design is the internationalization and modernization of ink and wash language. Through the creation of international visual language, the design works meet the aesthetic of the new age and are accepted by all the people and accepted by the public. As the designer Chen put the " The process of attention to the East and West culture and elements of comparison, it is possible to make our poster design to obtain more valuable creative results. "Wang ordered also said" posters through the image to convey information, should be an international language, ...... to convey the information expressed very clear, very concise, so that people of different cultures at a glance, and not because of the national character or uniqueness of graphic symbols weakened its function of transmission of information. "But the international Do not deny the national characteristics, must also pay attention to the design of the personality of the publicity, the characteristics of the national characteristics of these problems. Design must be made in the unity of change, the design of the national characteristics must not be weakened or disappeared due to internationalization, but should look for new development.

Ink and the use of elements in the design is not simply put on a layer of fashion coat thing, but not the old and new elements simply add. If you simply use the calligraphy to write English or use Chinese characters for international graphics, is very one-sided understanding of the traditional elements and modern international graphics relationship. Light directly from the traditional elements and graphics is meaningless, should understand its meaning, meaning and spirit, with the wisdom of the form of clever expression. "This prominent application of the traditional elements, not a simple retro, more is the traditional modeling elements for the material of the times, that is, by the traditional culture of the mouth, speak contemporary ideas, with classical symbolic language, construction The design pattern of modern graphics with a certain historical tradition. "[] In the way of thinking about design, we will first use the symbolic meaning of ink and oil elements to express some kind of interest, emotion and thought to re-create the ink elements, there are oriental shape and charm, but also has the meaning of modern design and form the final through the design of deep-seated ideas, reflecting the oriental national unique temperament, spirit, culture and philosophy. I summed up the three aspects of the use of modern visual design principles, inheritance deep ink elements, innovative surface ink elements.

\section{Conclusion}

As the essence and representative of Chinese culture, ink painting some of the concept and artistic methods, aesthetic concept worthy of graphic design research and reference. But it must also adapt to the rhythm and aesthetics of modern society, must conform to the laws and requirements of visual communication. In addition, the ink symbol to the rigid design to the design, can not be said 
to bring the traditional characteristics, but also need to interpret the ink in the infiltration of national wisdom, mood, spirit and other deeper elements, to deep into the modern design of modern elements in order to make our design for the domestic audience to accept, recognized by the world.

\section{References}

[1] Yu Fei. Talking about the application of traditional ink and ink elements in modern graphic design [J]. Commercial culture (the first half). 2011 (03)

[2] He Ping. On the characteristics of ink and ink elements in modern advertising design [J]. Fine Arts. 2010 (05)

[3] Lu Yulong. Let the traditional ink and wash elements in the modern graphic design blooming splendor [J]. Fine art. 2010 (05)

[4] Chen Hui, Guo Hong Lei. Traditional ink and ink elements in the application of modern advertising design [J]. Packaging Engineering. 2010 (14)

[5] Yuan Zhengbo. Talking about the application of Chinese ink and ink elements in graphic design [J]. Shaanxi Education (Higher Education Edition). 2010 (Z1)

[6] He Dezhen. Ink and ink elements - advertising design in the unique Chinese cultural symbols [J]. Academic Forum. 2009 (12) 